\title{
Socket Preservation: Allograft vs. Alloplast
}

Mehdi Sezavar ${ }^{1}$, Behnam Bohlouli ${ }^{1}$, Mohammad Hosein Kalantar Motamedi ${ }^{1 *}$, Jahanfar Jahanbani ${ }^{2}$ and Masoud Shah Hosseini ${ }^{3}$

${ }^{1}$ OMFS Department, Azad University of Medical Sciences, Tehran Dental branch, IR Iran

${ }^{2}$ Department of pathology, Azad University of Medical Sciences, Tehran Dental branch, IR Iran

${ }^{3}$ Dental student, Azad University of Medical Sciences, Tehran Dental branch, IR Iran

*Corresponding author: Motamedi MHK, OMFS Department, Azad University of Medical Sciences, Tehran Dental branch, Iran, Tel: 98- 9121937154; E-mail: motamedical@yahoo.com

Rec date: Apr 09, 2015, Acc date: Apr 21, 2015, Pub date: Apr 23, 2015

Copyright: ( 2015 Sezavar M, et al. This is an open-access article distributed under the terms of the Creative Commons Attribution License, which permits unrestricted use, distribution, and reproduction in any medium, provided the original author and source are credited.

\begin{abstract}
Background: The volume shrinkage of the alveolar ridge might be minimized by the ridge preservation stages and applied biomaterials, after tooth extraction.

Objectives: The aim of this study is to compare alloplastic with allograft in terms of preservation and bone regeneration of the alveolar ridge after tooth extraction.

Materials and Methods: This study clinically assessed this issue via the Split Mouth method which assessed 10 dental sockets filled with alloplasts and 9 others with allografts postextraction. The effectiveness of each material was clinically and histologically processed. The alveolar ridge width was measured by a gauge, before filling the socket and 2 months postextraction when inserting the dental implant. The histological process of bone samples were observed under light microscope at the time of fixture insertion to evaluate live and dead bone, trabecular, amorphous and non- osteoblastic. The changes in two groups in terms of the quantity underwent T-Test examination and the quality of bone regeneration was assessed using MANN-U-WHITNEY test. IRB and ethical approval was granted for our study.
\end{abstract}

Results: Minimal reduction of alveolar ridge widths were observed in both groups (reduction of alveolar ridge in the allograft group: $0.61 \mathrm{~mm} \pm 1.06$ and in the alloplast group: $0.85 \mathrm{~mm} \pm 0.88$ ) but the difference was not significant statistically $(P=0.6)$; no significant differences were noted in vital $(P=0.9)$, nonvital $(P<0.8)$, trabecular $(P<0.7)$ or amorphous $(P<0.4)$ bone.

Conclusion: Both materials were equal in terms of the quantity and the quality of osteoblasts and both were the same in terms of live and dead bone. No major differences in the regenerated bone could be found between these two groups.

Keywords: Allograft; Alloplast; Osteoblast; Dental socket preservation

\section{Introduction}

Alveolar bone loss is an inevitable consequence that occurs after tooth extraction. Transformation and resorption of the alveolar crest can create deformity [1]. Narrowing of the alveolar ridge can cause many problems in terms of cosmetic, functionality and dental implantation [2]. As the controlled clinical studies have reported, the average horizontal alveolar bone loss during the first year after atraumatic tooth extraction is 5 to $7 \mathrm{~mm}[3,4]$. The bone loss after tooth extraction will occur rapidly in the first 6 months in which up to $40 \%$ of the height and $60 \%$ of the width of the alveolar bone can be lost during this time [5]. These problems can be minimized following procedures of socket preservation of the extracted tooth. The best time to preserve the alveolar ridge is at the time of extraction [6]. The existing methods of ridge preservation include the use of autogenous, allogenic, xenogenous grafts and alloplasts with or without placement of absorbable and non -absorbable membranes [7-11]. In general, the allografts used by dental surgeons include: DFDBA, (decalcified freeze
- dried bone) FDBA (mineralized freeze-dried bone - allogenic graft) $[12,13]$. One of the proposed methods to maintain bone is to use an"alloplast"or"allograft" with similar size of particles. Since there are few studies of quantitative and qualitative methods to investigate the effect of socket preservation techniques after tooth extraction for dental implant treatment, this scientific and cost-effective study with the purpose of comparing the effect of Cenobone (Kish Tissue Regeneration, Iran) and Osteon II (GENOSS, Korea) on quality and quantity of the dental socket preservation of the patients who referred for implant surgery to our university from 2013-2014.

\section{Materials and Methods}

A total of 20 healthy patients with indication for dental implant placement were selected; patients with systemic bone disease, diabetes, pregnancy, history of radiation therapy and chronic use of corticosteroids were excluded from the study. Before surgery, chlorhexidine mouthwash $(0.2 \%)$ was used by the patients. If the patients were in pain, they were given ibuprofen $400 \mathrm{mg}$ every 6 hours, amoxicillin $500 \mathrm{mg}$ every 8 hours for seven days and $0.2 \%$ chlorhexidine mouthwash twice a day for two weeks. After allograft 
and alloplast placement in the dental socket after tooth extraction the cavity was closed primarily with 3-0 silk suture. At the next visit after 4 months later for the insertion of implants, samples from the tooth cavities which were filled with bone material were taken and after fixation in formaldehyde solution were delivered to the pathologist for histological studies. The selection of the allograft material used in the patient's socket was done via randomized stratification and as a result, 9 sockets were filled with allograft sand 10 sockets were filled with alloplasts (Cenobone group DFDBA group, Kish co., Iran). The samples then were placed in containers containing formaldehyde and were given to an oral pathologist. In the laboratory, according to standard methods, the samples were placed in $10 \%$ formic acid for decalcification for a week. Then they were cut longitudinally to a thickness of $6-8$ micron. Two to three layers of each sample were prepared and stained with hematoxylin and eosin method under magnifications of 10 and 150 of the objective lens and magnification of 15 lens were done to determine the rate of bone regeneration. Statistical analysis of factors related to bone regeneration was performed using T-Test. Changes in bone regeneration rate in both groups were performed using $\mathrm{T}$-Test and the quality of bone generation was performed using Mann-U-Whitney test. IRB and ethical approval was granted for our study.

\section{Results}

This study was performed on 19 dental sockets which of 10 contained alloplast, 9 of them contained allograft material. The patients were of men and women with an average age of $46 \pm 6$. The changes related to the width of the alveolar ridge on the bony crest are gathered in the study groups in Table 1 that shows the width of the alveolar ridge in Cenobone from allograft group, was $8.24 \pm 1.06 \mathrm{~mm}$ initially, and at the time of implantation (4 months later) was $7.60 \pm$ $1.06 \mathrm{~mm}$ (not statistically significant $=0.2$ ).

\begin{tabular}{|l|l|l|}
\hline & $\begin{array}{l}\text { Socket width before } \\
\text { study }\end{array}$ & $\begin{array}{l}\text { Socket width after 4 } \\
\text { months }\end{array}$ \\
\hline Allograft $(\mathrm{N}=9)$ & $8.24 \mathrm{~mm} \pm 1.06$ & $7.61 \mathrm{~mm} \pm 1.06$ \\
\hline Alloplast $(\mathrm{N} 2=10)$ & $8.55 \mathrm{~mm} \pm 1.05$ & $7.7 \mathrm{~mm} \pm 0.88$ \\
\hline Result & $\mathrm{P}<0.6$ & $\mathrm{P}<0.8$ \\
\hline
\end{tabular}

Table 1: Socket width measurements

The alveolar ridge width in Osteon II group, was been $8.55 \pm 1.05$ $\mathrm{mm}$ at first and at the time of implantation (4 months later) has changed to $7.7 \pm 0.88 \mathrm{~mm}$ that is statistically significant $(\mathrm{P}=0.05)$.

The reduction value of alveolar ridge of Cenobone group was $0.61 \pm$ $1.06 \mathrm{~mm}$ and the reduction value of alveolar ridge of alloplast group is $0.85 \pm 0.80 \mathrm{~mm}$, meaning the difference between the two values was not statistically significant $(\mathrm{P}=0.6)$.

The relative information of histological examinations of both Osteon II and Cenobone is shown in Table 2 which indicates that the percentage of vital bone in Cenobone group was $25 \pm 9.6 \mathrm{~mm}$ and in Osteon II group was $24.5 \pm 8.94 \mathrm{~mm}$; this difference was not statistically significant $(\mathrm{P}=0.9)$. The percentage of non-vital bone in Cenobone group was $32.22 \pm 4.41 \mathrm{~mm}$ and in Osteon II group was 33 $\pm 15.6 \mathrm{~mm}$; this difference was not statistically significant $(\mathrm{P}<0.8)$. Trabecular pattern in the Cenobone group was $17.77 \pm 10.6 \mathrm{~mm}$ and in alloplast group was $17 \pm 7.87 \mathrm{~mm}$, meaning their difference was not statistically significant $(\mathrm{P}<0.7)$. Also the percentage of amorphous bone pattern in Cenobone group was $8.33 \pm 4.2 \mathrm{~mm}$ and in Osteon II group was $10 \pm 3.3 \mathrm{~mm}$ and this difference was not statistically significant $(\mathrm{P}<0.4)$ and the percentage of non-osteoblastic bone in Cenobone group was $0.88 \pm 0.84 \mathrm{~mm}$ and in Osteon II group was 0.88 $\pm 0.74 \mathrm{~mm}$, and their difference was not statistically significant $(\mathrm{P}<0.9)$. In this study, vital and necrotic bone, trabecular, amorphous and non- osteoblastic were found in the Cenobone group to be: vital bone $25 \pm 9.6$, necrotic bone $32.22 \pm 4.41$, trabecular $17.77 \pm 0.6$, osteoblastic $8.33 \pm 4.2$ and non-osteoblastic $0.88 \pm 0.84$ and in the alloplast group was: vital bone $24.5 \pm 9.84$, necrotic bone $33 \pm 15.6$, trabecular $17 \pm 7.87$, osteoblastic $10 \pm 3.3$ and non-osteoblastic $0.88 \pm$ 0.74 .

\begin{tabular}{|c|c|c|c|c|c|}
\hline & $\begin{array}{l}\text { Amorpho } \\
\text { us bone }\end{array}$ & $\begin{array}{l}\text { Trabecul } \\
\text { ar pattern }\end{array}$ & $\begin{array}{l}\text { Non-vital } \\
\text { bone }\end{array}$ & $\begin{array}{l}\text { Vital } \\
\text { bone }\end{array}$ & $\begin{array}{l}\text { Non- } \\
\text { osteoblas } \\
\text { tic }\end{array}$ \\
\hline Allograft $(\mathrm{N}=9)$ & $8.33 \pm 4.2$ & $\begin{array}{ll}17.77 & \pm \\
10.6 & \end{array}$ & $\begin{array}{l}32.22 \quad \pm \\
4.41\end{array}$ & $25 \pm 9.6$ & $\begin{array}{l}0.88 \\
0.84\end{array}$ \\
\hline $\begin{array}{l}\text { Alloplast } \\
(\mathrm{N} 2=10)\end{array}$ & $10 \pm 3.3$ & $17 \pm 7.87$ & $33 \pm 15.6$ & $\begin{array}{ll}24.5 & \pm \\
8.94 & \end{array}$ & $\begin{array}{l}0.88 \\
0.74\end{array}$ \\
\hline Result & $\mathrm{P}<0.4$ & $\mathrm{P}<0.7$ & $\mathrm{P}<0.8$ & $P<0.9$ & $P<09$ \\
\hline
\end{tabular}

Table 2: Percentage and type of bone formation

\section{Discussion}

The effect of both the alloplast and allograft on the quality and quantity of bone regeneration of dental socket were compared, after tooth extraction and before loading the implant.

The results showed no significant differences between the alloplast and allograft in terms of the quantity of bone regeneration in the dental socket and neither was any significant differences observed in the vital and necrosis of bone, trabecular ornon-osteoblastic. In this study, the minimum loss in the alveolar ridge width was observed in both groups after 4 months and in all cases implants were successfully fitted and then loaded on time.

Sarkarat et al. studied the effects of two allografts DFDBA (Osseo + Cenobone) with Acellular Dermal matrix membrane in alveolar bone preservation which were then compared [14]; the value of the vertical height of alveolar ridge located in MB, Mid-P, DB, Mid-B areas, decreased in both groups in 3 months, the rate was not statistically significant.

Although in our study, the decrease in both height and width of the alveolar ridge was observed in both groups during the 4 months, but it was not statistically significant $(\mathrm{p}=0.6)$.

In this study, the width of the alveolar ridge in both groups decreased during the 4 months period and the allograft socket measurement was $8.24 \pm 1.06$ and the alloplast socket was $8.55 \pm$ $1.05 \mathrm{~mm}$ before applying them both to their appointed sockets.

Sarkarat et al. studied the percentage of vital and necrotic bone, trabecular and the quantity of osteoblasts in allografts to be: vital bones $36.65 \pm 7.95$, necrotic bone $13.88 \pm 7.58$, trabecular $33.93 \pm 9.3$ and non-osteoblastic $6.98 \pm 1.57$; these results are comparable in both groups in accordance to our study.

Better maturation of bone tissue in the present study compared to Sarkarat et al. study, surely indicates the influence of time. This study 
Page 3 of 3

was processed at 4 months while the former was done at 3 months [14].

Iesella et al. studied the alveolar bone ridge preservation with freeze-dried allograft and collagen membrane compared to the tooth extraction alone in the implanting area. The results at the end did indicate a significant volume loss in the alveolar height and width in the extraction alone group compared to the ridge preservation group. There was also more bone regenerated histologically, in the ridge preservation group in accordance with the results obtained in the present study. Less volume loss in alveolar ridge width and desired bone regeneration were observed in both Cenobone and Osteon II groups.

In Iesella et al. study, FDBA group was used compared to DFBBA group which was used in the present study. FDBA is considered as an osteo-conductive material as DFDBA is a bonding osteo- inductive and has been also recognized as a more potential osteogenic material than FDBA in clinical studies, therefore it is more preferable [11].

In 2008, Tudor et al. studied a subject which was entitled as bone regeneration in bone defects with the use of human allograft particles and organic materials called Navigraft. These two types of materials, allograft and Navigraft provide clinical needs as a bone substitute and developments of bone regeneration in the bone defects which is all coordinated by DFDBA, the allograft group that has been used in the present study [15].

In 2006, Jensen et al.'s Study of autograft and allograft bone healing and re-absorption of B-Tricalcium phosphate an organic bovine bone was conducted and as a final point, it did demonstrate that both of $\mathrm{ABB}, \mathrm{B}-\mathrm{Tcp}$ can be replaced with autografts in bone reconstruction surgery [16].

In an Autograft surgery, which produces unintended injury or trauma to other parts of the body, there is certainly a good alternative for the transplantation to be replaced by the same healing power and the need for surgical harvesting of graft material to fulfill, they will be all to the benefit of patients and practitioners, therefore allografts were used as a socket preservation material in the present study [17].

In 2014, Kotsakis et al. studied alternative materials to keep the sockets preserved using substituted materials such as inorganic bovine bone and calcium phosphosilicate putty bone which did indicate that there was a slight volume loss in the ridge width of the sockets in both PUT $(1.26 \pm 0.41 \mathrm{~mm})$ and BOV $(1.39 \pm 0.57 \mathrm{~mm})$ groups compared to the control group $(2.5 \pm 0.59 \mathrm{~mm})$ which no materials was used in their sockets and finally Kotsakis et al. reported that both the BOV and PUT can be used to preserve sockets [18].

The limitation of this study was the small sample size and short follow-up.

\section{Conclusion}

Although the socket preservation treatment cannot prevent the ridge volume loss buccolingually, but it can minimize it vertically. Considering the importance of the soft and hard tissue for cosmetic and functional purposes, especially in the anterior teeth set, socket preservation method is recommended and the use of alloplasts and allografts in preserving dental socket either in quantity or quality at the four- month follow up had similar results.

\section{References}

1. Mecall RA, RosenFeld AL (1991) Influence of residual ridge resorption pattern on implant fixture placement and tooth position. Int J perisdontics Restoratire Dent 11: 8-23.

2. Fotek PD, Neiva RF, Wang HL (2009) Comparison of dermal matrix and polytetrafluoroethylene membrane for socket bone augmentation: a clinical and histologic study. J Periodontol 80: 776-785.

3. Lekovic V, Kenney EB, Weinlaender M, Han T, Klokkevold P, et al. (1997) A bone regenerative approach to alveolar ridge maintenance following tooth extraction. Report of 10 cases. J Periodontol 68: 563-570.

4. Lekovic V, Camargo PM, Klokkevold PR, Weinlaender M, Kenney EB, et al. (1998) Preservation of alveolar bone in extraction sockets using bioabsorbable membranes. J Periodontol 69: 1044-1049.

5. Shi B, Zhou Y, Wang YN, Cheng XR (2007) Alveolar ridge preservation prior to implant placement with surgical - grade calcium sulfate and platelet-rich plasma: a pilot study in canine model. Int $\mathrm{J}$ oral maxillfac implants. 22: 656-665.

6. Irinakis T (2006) Rationale for socket preservation after extraction of a single-rooted tooth when planning for future implant placement. J Can Dent Assoc 72: 917-922.

7. Nemcovsky CE, Serfaty V (1996) Alveolar ridge preservation following extraction of maxillary anterior teeth. Report on 23 consecutive cases. J Periodontol 67: 390-395.

8. Stanley HR, Hall MB, Clark AE, King CJ 3rd, Hench LL, et al. (1997) Using $45 \mathrm{~S} 5$ bioglass cones as endosseous ridge maintenance implants to prevent alveolar ridge resorption: a 5-year evaluation. Int J Oral Maxillofac Implants 12: 95-105.

9. Brugnami F, Then PR, Moroi H, Leone CW (1996) Histologic evaluation of human extraction sockets treated with demineralized freeze-dried bone allograft (DFDBA) and cell occlusive membrane. J Periodontol 67: 821-825.

10. Sclar AG (2004) Strategies for management of single-tooth extraction sites in aesthetic implant therapy. J Oral Maxillofac Surg 62: 90-105.

11. Iasella JM, Greenwell H, Miller RL, Hill M, Drisko C, et al. (2003) Ridge preservation with freeze-dried bone allograft and a collagen membrane compared to extraction alone for implant site development: a clinical and histologic study in humans. J Periodontol 74: 990-999.

12. Lekovic V, Camargo PM, Klokkevold PR, Weinlaender M, Kenney EB, et al. (1998) Preservation of alveolar bone in extraction sockets using bioabsorbable membranes. J Periodontol 69: 1044-1049.

13. Nucgack G, Bewnabm Gebrt G, Tajeum Fernub A, Carrabzai (2002) Carranza's clinical periodontology, 9th edn WB Sounders Co.

14. Sarkarat F, Safri D, Bohlooli B ,Lozanis (2010) Ridge Preservation with osseot compared to cenobone for implant site development: aclinical and histologic study in human. Journal Res Dent Sci 7: 1-7.

15. Simon BI, Zatcoff AL, Kongjj, o'connel SM (2009) clinicaly and histlogicalcomparation of exraction socket Healing following the use of Auto logous Platelet Rich Fibrin matrix (PRFM) to Ribse preservation procedures employing Demineralized Freeze dried bone allograft material and membrane. Open Dent J 3: 92-99.

16. Jensen SS, Broggini N, Hjørting-Hansen E, Schenk R, Buser D (2006) Bone healing and graft resorption of autograft, anorganic bovine bone and beta-tricalcium phosphate. A histologic and histomorphometric study in the mandibles of minipigs. Clin Oral Implants Res 17: 237-243.

17. Mellonig JT, Bowers GM, Bailey RC (1981) Comparison of bone graft materials. Part I. New bone formation with autografts and allografts determined by Strontium-85. J Periodontol 52: 291-296.

18. Kotsakis GA, Salama M, Chrepa V, Hinrichs JE, Gaillard P (2014) A randomized, blinded, controlled clinical study of particulate anorganic bovine bone mineral and calcium phosphosilicate putty bone substitutes for socket preservation. Int J Oral Maxillofac Implants 29: 141-151. 